\title{
DIGITAL INDIA: CHALLENGES, SOLUTIONS AND ITS IMPACT ON SOCIETY
}

\author{
NEENA JINDAL, KRITIKA THAKUR \& TANIA SHARMA
}

Jaypee University of Information Technology, Waknaghat, Solan, Himachal Pradesh, India

\section{ABSTRACT}

A programme that focuses on bringing about a transformation by putting together Indian talent and Information Technology together to form a better India in the future, and a vision to transform the country into a well empowered digital community and an economy with a plethora of knowledge was accomplished by the Government of India. The government of India came with a flagship programme namely "Digital India". Under this campaign, electronic services are being strengthened by reducing paperwork. This has turned out to be a fruitful transformation technique to take off the weight of investing time over paperwork and devoting man labor in various fields, which is effective as well as efficient. Mr. Narendra Modi, the active prime minister of India, played a crucial role in furnishing this campaign. Facilitation of E-governance being the aim by providing better e-services, boosting youth to reduce paperwork and time savage. The major idea of connecting people residing in rural areas or remote areas with urban technology was considered to be a myth. It is now success and the fulltime utilization is being minimized by providing high-speed internet services to villagers through their required work, that would be done in a single click without traveling to urban offices. Portals like M Kisan portal are serving farmers with great information regarding their crop yield, weather conditions and upgrading them with upcoming diseases are unable to fill the voids due to reduced literacy rate in India. Making India secure in terms of cyber is the major challenge faced nowadays.

KEYWORDS: Digital India, E-Services, E-Governance, Transformation \& Digitalization

Received: Jan 25, 2019; Accepted: Feb 15, 2019; Published: Feb 28, 2019; Paper Id.: IJEEFUSAPR20197

\section{INTRODUCTION}

A programme that focuses on bringing about a transformation by putting together Indian talent and Information Technology together to form a better India in the future. A vision to transform our country "INDIA" into a well-empowered digital community and an economy with a plethora of knowledge was accomplished by the Government of India. They came with a flagship programme namely "Digital India". This programme was inaugurated on July 1, 2015, in the esteemed presence of a plethora of top business tycoons like Cyrus Mistry (chairman of TATA group), Mukesh Ambani (chairman of Reliance group), Azim Premji (chairman of WIPRO) etc. with the major agenda, to improve infrastructure, delivering services and literacy digitally. Electronic services are being strengthened by reducing paperwork. This has turned out to be a fruitful transformation technique to reduce the efforts of investing time over documentation and devoting workforce in various fields, which is productive as well as constructive. Mr. Narendra Modi, the active prime minister, played a crucial role in furnishing this campaign. Facilitation of E-governance is the aim by providing better e-services. The major idea of connecting people residing in rural areas or remote areas with urban technology which was considered to be a myth is now successful by time utilization being minimized by providing high-speed internet services to villagers, through which their required work would be done in a single click without traveling to urban offices. BSNL takes an initiative to provide more than 300,000 villages and residential areas with high-speed internet connections form 
the layout of the programme. India would get more technology-oriented. This project has been scheduled to be completed by 2019 with the financing of leading companies (national or international). Mr. Ambani stated to fund about 2.5 lac crore in the digital India project, which is an appreciable effort of the Reliance group.

In this study, we are going to study the major challenges in the accomplishment of Digital India and further, it will be proposed that what can be done to provide a solution to the programme. It will also be seen what type of impact is shown by the digitalization by society.

\section{OBJECTIVES}

- To study the concept of digital India.

- To find out the challenges that come for the implementation of digitalization.

- To find solutions to the implementation of the programme.

Meaning of Digital India: A campaign launched by the Indian government to ensure that the services of government are made easily available to all the citizens electronically and are accessible with improved facilities of infrastructure online. The concept of making our country authorized digitally in the field of technology. Various plans are being proposed to make this campaign successful which consists of three core components:

- Digital infrastructure is stable and secure.

- Government services delivery digitally

- Development in digital literacy.

- Providing high-speed internet in rural areas.

Every coin has two sides so does Digital India have. Introducing digital India to the people in a developing country itself brings about challenges along with the technology. In a country like India, where people are still struggling for their three meals, technology can increase their battle. Proposing the technology to the folks cannot serve their various day to day issues until the process is not easily understood by the community. Although portals like M Kisan portal are serving farmers with great information regarding their crop yield, weather conditions and upgrading them with upcoming diseases are unable to fill the voids due to reduced literacy rate in India. Making India secure in terms of cyber is the major challenge faced nowadays.

\section{NINE PILLARS}

In order to prepare India for the knowledge-based modification and providing good governance to people by synchronized and coordinated involvement with both the central government and local government, the Digital India is based on nine pillars. 


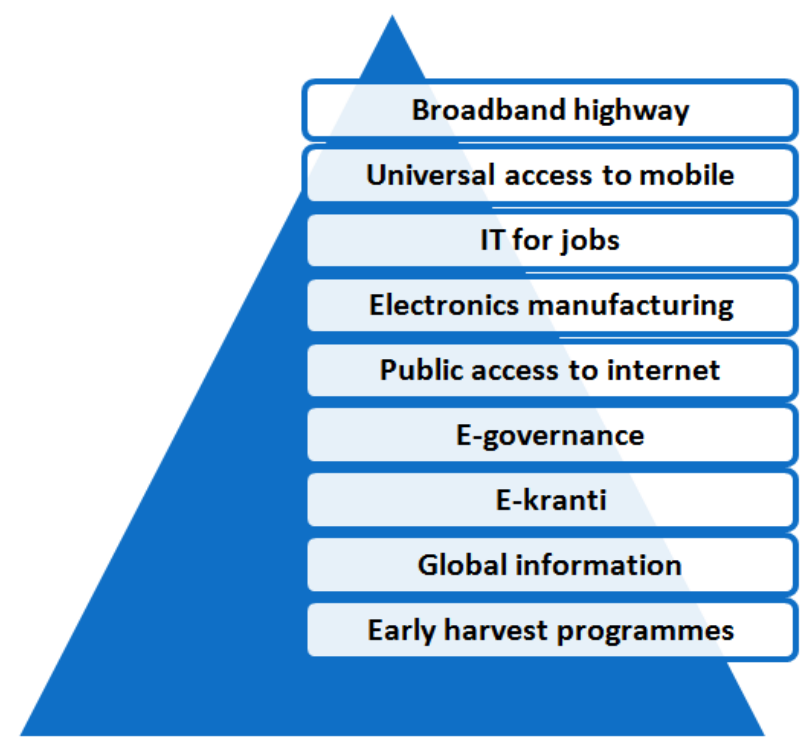

Figure 1: Nine Pillars of Digital India

Broadband Highways: Government focus to provide national optical fiber network (NOFN) in all panchayats. Broadband for the rural will be laid by December 2016 and Virtual Network Operators would be an upliftment for service delivery and communication infrastructure.

Universal Access to Phones: The government took initiative to ensure that by 2019 all villages would be covered through mobile connectivity. The aim was to enhance network penetration and cover loopholes in all 44,000 villages.

Public Internet Access Programme: This programme has sub-components which are Common Services Centre (CSC) and Post Offices as a multi-service center. CSCs would be firmed and its number would be increased to 250,000. DeitY would be the department to propagate the scheme.

E-Governance- Reforming Govt. through Technology: All databases and information should be in electronic form and not in the manual form which keeps transparency of these processes to citizens. IT should be enforced to automate, respond and analyze data to identify and resolve persistent and upcoming problems. Documents will be provided online for a faster examination of data.

E-Kranti: Information regarding several areas like education, health, agriculture is covered through this. All services are in the form of electronic and relief people from all documentation. Citizens need not struggle and stand in a queue in order to process their work. Digitalization is the era of electronic and digital services.

Information for All: This is an open data platform which promoted the release of datasets in an open format by departments for use, reuse and redistribution. Online hosting of information and documents would promote open and easy access to information for citizens. Hosting data online and engaging social media platforms for governance is the aim of the government. People can send in their suggestions and comment on various issues raised by the government. MyGovt is one such platform for Citizen Engagement towards good governance in India.

Electronics Manufacturing: The government aims at no imported commodity electronics. The government focuses to accomplish this by putting up smart energy meters, micro ATMs, mobile, consumer and medical electronic systems. 
IT for Jobs: The government aims to train about 1 crore students from small towns, cities, and villages for the IT sector by 2020, which is for the purpose of setting up BPO sectors in various states of the country.

Early Harvest Programs: It aims at setting up WiFi and Aadhar Allowed Fingerprinting Presence Program in all the states of the country. Online documentation of attendance would be initiated.

\section{Vision of the Digital India Programme by Govt. of India}

Mr. Narendra Modi, honorable prime minister of India quoted, "We want to have one mission and target: Take the nation forward - Digitally and Economically." An empowered community and knowledge economy with a vision that is beyond any dream. This programme focuses on three key vision areas depicted in figure 2 .

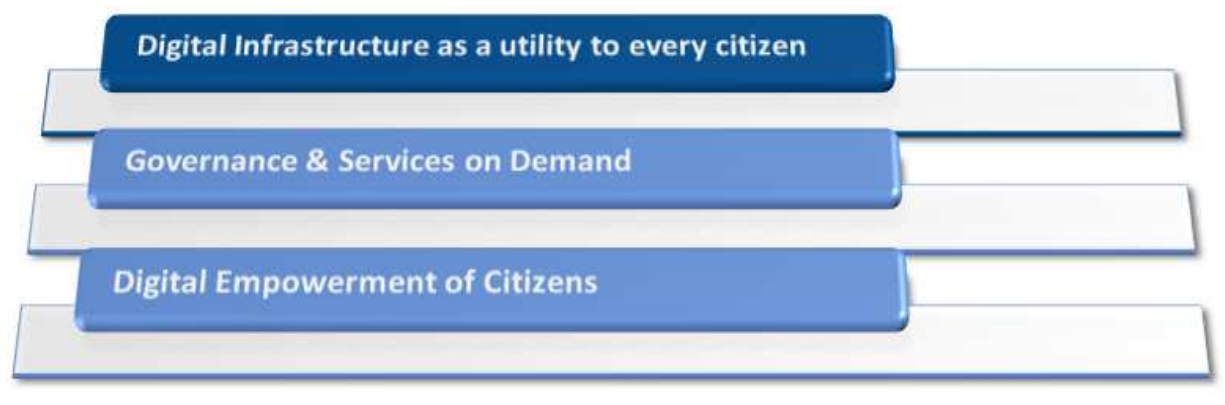

Figure 2: Vision of Programme

Digital Infrastructure as a utility to every citizen, states that a well-connected nation is a prerequisite to a wellserved nation. As soon as the backward areas would be connected through high-speed internet, then e-governance services would be achieved socially and financially. This digital infrastructure provide citizens of India with digital identification which is exclusive, lifelong, online and authenticity. Easy accessibility to the Common Service Centre enabling a digital and financial space which is safe and secured in cyberspace. The major role in infrastructure is played by:

- AADHAAR

- $\quad$ BHARAT BROADBAND NETWORK (BBNL)

- CENTRE FOR EXCELLENCE FOR INTERNET OF THINGS (COE-IT)

- $\quad$ CERT-In

- $\quad$ CYBER SWACHHTA KENDRA

- MOBILE SEVA APP STORE

- $\quad$ SINGLE WINDOW INTERFACE FOR TRADE (SWIFT)

Governance \& Services on Demand, sincere efforts have been made by the state governments to improve the delivery of public services. Various key points that are brought up include integrated services, financial transactions (electronic or cashless), and improved-digitally transformed services. Some services are enlisted below.

- Accessible India Campaign Mobile App

- $\quad$ Agri Market App

- $\quad$ BHIM 
- crop insurance Mobile App

- Digital AIIMS

- E-Panchayat

- E-Samparak

- E-Visa

- Geographic Information System

- Madaad App

- UMANG

- UDAAN

- Soil Health Card

Digital Empowerment of Citizens, focuses on digital knowledge, digital resources, and digital platforms. It allows citizens to submit documents and certificates online. Resource availability in Indian languages. Scheme playing a major role in it are listed below.

- $\quad$ AADHAR Enabled Payment System

- $\quad$ BPO Scheme

- DigiDhan ABHIYAAN

- MyGov

- NREGA-SOFT

- OPEN FORGE

- PAHAL

- PRADHAN MANTRI JAN DHAN YOJANA (PMJDY)

- SMART CITIES

- TARGETED PUBLIC DISTRIBUTION SYSTEM (TPDS)

\section{IMPACTS OF DIGITALIZATION ON SOCIETY}

\section{Positive Impacts}

- This ensures the transparency of data between the government and the citizens.

- People have shifted from hard work to smart work.

- Field of agriculture is enhanced and is equippedwith the latest technologies which help farmers to bring good quality and quantity of crops.

- Masses prefer to stay in villages as even remote areas have been provided with the coverage of the internet. 
- Paperwork is reduced therefore consumption ofnatural resources for the manufacturing of paper has been reduced.

\section{Negative Impacts}

- Although services of wi-fi enhance the lifestyle, people still have to face problems regarding the speed of the internet and cybercrime.

- Reduction of paperwork leads to the exposure of wi-fi radiations, computer radiations which affect the health of an individual.

- Using electronic devices leads to more production of them; therefore, more electronic waste is generated.

- $\quad$ Providing internet needs to have a check on issues like net neutrality.

- Implementation of Protocol by various departments is a cumbersome process.

\section{CHALLENGES OF DIGITAL INDIA}

- Creating awareness amongst the people, especially in rural areas regarding digital India is the major challenge.

- Exposure and accessibility to various fields using the internet also contribute to the cybercrime.

- India's Digital Insufficient infrastructure for the online transactions comes as one the challenge.

- India being a diverse country in terms of culture, tradition, caste, and creed has to face difficulties in merging technology with language.

- Regulation of protocol and its implementation is another problem faced.

- Using electronic gadgets may emit several radiations, for example, computer radiation, Wi-Fi radiations which are harmful to health.

- As physical activities have been reduced through this programme health issues are the areas of concern.

- Portals like M-Kissan provides information regarding the diseases related to plants, due to inadequate awareness about the irrigation and farming people cannot make proper use of the facilities provided by the government.

\section{What can be Done?}

- Various seminars and programmes shall be conducted among the masses so as to deliver the knowledge regarding the digitalization.

- Several institutions may include courses that offer adequate information with reference to Digital India.

- Active participation is required of various departments which deals with the implementation of the digitalization.

- $\quad$ Availability of the services in more than one language can be more helpful to the masses.

- $\quad$ Proper authentication of the documents should be there in order to reduce the cybercrime.

- There should be proper instructions to regulate the protocols used in the process as it varies with hardware and software devices. 


\section{CONCLUSIONS}

Technology is that tool, which can be proved both beneficial and harmful to the society, it depends on the individual using it. Digital India is one such tool, if implemented accurately can be proved extremely profitable to the masses. It not only can bring employment to the youth especially in the field of electronics and computer science, but can help the old age people as well. People living in rural areas are also benefited by the programme, as they no longer have to move to the cities for various reasons. It is the responsibility of every individual to make proper use of the opportunities and make others also to do so. This programme enhances literacy rates and the development of our nation.

\section{LIMITATION OF STUDY AND SCOPE FOR FUTURE RESEARCH}

Through this programme, the government aims to provide Wi-Fi facilities to all institutions across the country. Thus the facility provided by the government is not accessed by the people and the issues related to the internet services still persists. Therefore, proper track of services should be there. Digital India is contributing in every field and keeping good supervision on things. Other services provided by the government like mid-day meal to the Primary section of the school, merging the services of Digital India with Mid-day meal would enhance the quality of food provided and can be regulated through this.

\section{ACKNOWLEDGEMENTS}

Authors are grateful to Jaypee university of information technology for allowing them to carried out this research.

\section{REFERENCES}

1. Padhi Priyadarshini, (2017) 'Digital India: issues and challenges', International Journal of IT and management, vol no. 7(50), pp $44-49$.

2. Mohanta Giridhari, Debasish Sathya Swaroop, Nanda Sudipta Kishore, (2017) 'A study on growth and prospect of digital India campaign', Saudi Journal of Business and Management Studies, vol no. 2(7),pp 727-731.

3. Ghounane, N. (2014). A sociolinguistic view of linguistic taboos and euphemistic strategies in the Algerian Society: Attitudes and beliefs in Tlemcen speech community. International Journal of Research in Applied, Natural and Social Sciences, 2(3), 73-88.

4. Sharma Aditya, Sharma Kavish,(2015) Digital India a new change in the Indian economy, EPRA International journal of the economic and business review, vol no. 3,(12).

5. https://www.digitalindia.gov.in/

6. https://en.wikipedia.org/wiki/Digital_India 
